\title{
A EDUCAÇÃo INTEGRAL NO BRASIL: UMA ANÁLISE HISTÓRICO-SOCIOLÓGICA
}

\author{
INTEGRAL EDUCATION IN BRAZIL: A SOCIAL-HISTORICAL ANALISIS
}

DOI: http://dx.doi.org/10.23926/RPD.2526-2149.2018.v3.n2.p813-829.id234

\section{Thiago Dutra \\ Mestre em Educação em \\ Ciências (UFRGS). \\ thiagodutrac@hotmail.com}

\section{Jaqueline Moll}

Pós-Doutorado em Educação (UFRJ).

Professora titular da Faculdade de Educação (PUC-RJ).

jaquelinemoll@gmail.com
Resumo: A perspectiva contemporânea de educação integral é um direito do cidadão brasileiro respaldado por diferentes marcos legais, concebendo o ser humano em suas múltiplas dimensões e problematizando as finalidades e metodologias aplicadas no sistema atual, se torna uma possibilidade para se superar a crise educacional da atualidade. O Brasil historicamente teve pouca preocupação com a educação dos cidadãos, mas nas experiências que tivemos podemos analisar algumas concepções que se aproximavam da educação integral enquanto outras eram opostas aos princípios que essa defende. A metodologia utilizada vem da história cultural, onde a partir das contribuições de autores como Peter Burke e Jacques Le Goff buscou-se recortes de longa duração visando a construção de um processo de bricolagem, formando 'uma' história da educação integral no Brasil através de autores que tratam do tema. Essa disputa de perspectivas acirra-se, nos dias atuais, nas disputas de projetos de governo na área da educação.

Palavras-chave: Educação integral. Políticas públicas. História da educação.

\begin{abstract}
The integral education's current perspective is the Brazilian's citizen rights, backed up by legal frameworks, becomes a possibility to overcome the educational crisis nowadays. Thus it is possible to conceive the human being through its multiple dimensions, focusing in the objectives and in the methodology applied. Historically Brazil had poor worries in terms of education with their citizens, but, in our experiences, we could analyze some conceptions approaching the integral, while others keep opposition from the principles. The methodology used comes from the cultural history contributions that some authors such as Peter Burke and Jacques Le Goff developed. This study has been done as a bricolage process during a long period, creating 'one' integral education history in Brazil. This perspective debate is identified in government projects being disputed for the educational area.
\end{abstract}

Keywords: Integral education. Public politics. History of education. 


\section{INTRODUÇÃO}

A escola passa por fortes críticas sobre seus métodos, conteúdos e objetivos, tanto por parte de seus teóricos como por professores, alunos e comunidade. O conteudismo, o currículo estagnado e desconectado da realidade dos educandos, o sistema de aula baseado na exposição do professor ou fixado no livro didático, a falta de atratividade da escola para o jovem, todos esses fatores colaboram para um baixo aprendizado e para altas taxas de repetência e evasão vistas na realidade das escolas públicas no Brasil ${ }^{1}$.

A educação integral responde as necessidades de mudança quantitativa e qualitativa da educação brasileira, através da ampliação do tempo escolar e do reconhecimento do dever de se trabalhar as múltiplas dimensões do ser humano. Podemos falar hoje de um paradigma contemporâneo de educação integral (MOLL, 2012) que se alicerça em um conjunto de pressupostos básicos: uma escola pública, gratuita e de qualidade; a abertura da escola para a comunidade; valorização dos saberes populares; revisão dos currículos; articulação de diferentes campos e ações políticas; na escuta das crianças e jovens, encarando-os como sujeitos e não objetos; e preocupada com as problemáticas da contemporaneidade.

O artigo tem três objetivos a partir da questão: como a educação integral é assegurada enquanto direito do cidadão brasileiro e como as experiências educacionais na história da educação no Brasil ora se aproximam dessa perspectiva, ora se afastam? O primeiro objetivo é realizar uma análise documental dos marcos legais que versam, direta ou indiretamente, sobre o direito à educação integral.

Esse artigo é em sua totalidade uma análise bibliográfica e de textos legais e jornalísticos, em relação aos quais, devemos compartilhar alguns pressupostos teóricos de onde nos pautamos. As análises dos textos são problematizações de verdades como nos fala Foucault (2003), assim, procura-se compreender sua exterioridade, ou seja, sua contextualização e formação, quais as condições que tornam um discurso verdadeiro num determinado contexto social. Deve-se olhar para o entorno de um texto se queremos compreendê-lo, e após feito isso é necessário ter em mente que o modo como acontece a interação do pesquisador com o material já é uma imposição de significados (SARAIVA, 2009).

O segundo objetivo é construir uma breve retrospectiva histórica de práticas e perspectivas que ao longo da história do Brasil se aproximam ou se afastam das noções atuais de educar o sujeito em sua integralidade. Para tal buscou-se referências bibliográficas que

\footnotetext{
${ }^{1}$ Para ver os dados de defasagem idade série acessar: <http://portal.inep.gov.br/indicadores-educacionais>.
} 
apresentassem experiências diversificadas, tanto próximas quanto extremamente diferenciadas conceitual e metodologicamente. Resguardando as suas especificidades conjunturais podemos analisar possíveis raízes dessa perspectiva contemporânea de educação integral.

Essa análise historiográfica acompanha as perspectivas da história cultural, preocupando-se em fazer um recorte de um período de longa duração com um objetivo específico (BURKE, 1992), no caso, ressaltar momentos e experiências na história da educação do Brasil considerados relevantes enquanto marcas nas estruturas de mentalidades por trás da disputa entre os que defendem uma educação integral ${ }^{2}$ e os que lutam para manter a escola presa em seu modelo "tradicional".

O último objetivo é analisar o cenário atual das políticas públicas nessa área, mapeando os avanços e retrocessos ocorridos até o ano de 2016. Essa abordagem baseia-se na análise de reportagens e entrevistas apresentadas em páginas na internet sobre educação integral ${ }^{3}$, e em análises feitas por estudiosos sobre as últimas decisões políticas em educação. Podemos notar os projetos de sociedade que estão em disputa nessas propostas de educação, uma que busca oferecer uma educação que vise a complexidade humana e outra que busca manter os estudantes em uma educação direcionada às necessidades do mercado.

\section{A EDUCAÇÃO INTEGRAL É UM DIREITO DO CIDADÃO BRASILEIRO}

A construção de uma educação integral é papel do estado e direito do cidadão, como aponta a legislação educacional brasileira nos artigos 205, 206 e 227 da Constituição Federal, no Estatuto da Criança e do Adolescente (ECA, Lei n. 9.089/1990), nos artigos 34 e 87 da Lei de Diretrizes e Bases da Educação Nacional (LDB, Lei n. 9.394/1996), no Plano Nacional de Educação (PNE, Lei n.10.179/01), e no Fundo Nacional de Manutenção e Desenvolvimento do Ensino Fundamental e de Valorização do Magistério (FUNDEB, Lei n.11.494/07). A proposta do novo PNE prevê que metade das escolas públicas brasileiras ofereçam a educação integral para pelo menos $25 \%$ de seus estudantes até $2020^{4}$.

A Constituição Federal de 1988 apresenta três artigos referentes à educação integral. No artigo 205 a educação é ressaltada enquanto direito humano devendo ser resguardada e

\footnotetext{
${ }^{2}$ São muitas as vertentes possíveis ao falarmos de educação integral, sendo esse conceito utilizado em diferentes contextos ideológicos, no Brasil nas décadas de 1920 e 1930 o movimento integralista usou esse termo para montar sua proposta de educação. Esse movimento carregava fortes marcas fascistas, marcando essa perspectiva pedagógica com traços autoritários que se pautavam no Estado, na família e na religião católica, buscando a ordem e o controle social (CAVALARI, 1999).

${ }^{3}$ Principalmente o site do Centro de Referências em Educação Integral: 〈http://educacaointegral.org.br/>.

${ }^{4}$ A legislação referida é facilmente encontrada nos sites do governo: 〈http://portal.mec.gov.br/legislacao〉.
} 
incentivada pela sociedade. O artigo 206 aponta a necessidade de gestão democrática na educação pública, elencando a intersetorialidade como eixo de fundamento. O artigo 227 trata de forma mais direta sobre a educação integral, afirma ser dever da família, da sociedade e do Estado assegurar o direito a educação, dentre outros como os direitos à saúde, alimentação, lazer, cultura, dignidade e liberdade, os ressalvando da violência, negligência e opressão. A ênfase geral gira em torna do direito a um pleno desenvolvimento da pessoa, tanto do ponto de vista cognitivo, como social e cultural.

O ECA reforça a perspectiva de educação integral em alguns artigos, por exemplo, ao versar sobre a importância de aprender em outros espaços que não sejam no âmbito da escola. No artigo 53 é apontado o direito de toda criança e adolescente à uma educação que foque no seu desenvolvimento pleno, direcionado para a vida e para a prática da cidadania, o qualificando assim para as demandas sociais contemporâneas e para o mundo do trabalho atual. O artigo 59 diz que municípios, estados e União devem facilitar recursos e estimular o acesso à espaços culturais, esportivos e de lazer.

A LDB apresenta algumas referências à educação integral. $\mathrm{O}$ artigo $2^{\circ}$ diz que a educação deve ser baseada em princípios de liberdade e solidariedade, afirma a finalidade da educação sendo o pleno desenvolvimento do educando e sua preparação para o exercício da cidadania, prevendo uma educação em diálogo com os diversos setores da sociedade. Os artigos 34 e 86 apontam a implementação de forma progressiva do tempo integral (jornada diária estendida) nas escolas de ensino fundamental.

O Plano de Desenvolvimento da Educação (PDE) foi aprovado em 2007 com o objetivo de melhorar todas as etapas da educação básica no Brasil. Uma das ações de melhoria contidas no PDE foi o Programa Mais Educação, que prevê a ampliação da educação em tempo integral no país, sendo um indutor para políticas de educação integral nos estados e municípios brasileiros.

O primeiro PNE vigorou desde a redemocratização do Brasil até 2010 e, dentre suas metas, propunha sobre a Educação Fundamental em sua meta II um modelo de educação de tempo integral para a etapa. Visava manter o processo de universalização do ensino e diminuir as taxas de retenção, priorizando as suas vagas para famílias de baixa renda, aumentando o tempo da jornada escolar para sete horas diárias.

O FUNDEB apresenta como objetivo a destinação de recursos para todas as etapas da educação básica pública, que compreende as Creches, Pré-Escolas, Educação Infantil, Ensino Fundamental, Ensino Médio e Educação de Jovens e Adultos. O fundo é uma reserva da União 
que visa complementar as verbas para a educação. Em $1^{\circ}$ de julho de 2010 foi aprovada a Portaria 873 sobre o Financiamento da Educação Integral, prevendo verbas do FUNDEB para a implementação da educação integral.

O segundo PNE, sancionado em 25 de junho de 2014, avança na implementação da educação integral pública e de qualidade tornando essa modalidade uma meta a ser atingida em todo país. A meta número 6 do PNE II prevê a oferta de educação em tempo integral para no mínimo $50 \%$ das escolas públicas e o atendimento de pelo menos $25 \%$ dos estudantes de educação básica do Brasil. A meta número 1 sobre a educação infantil prevê o estímulo a uma educação infantil em tempo integral para todas as crianças até cinco anos, como estabelecido nas Diretrizes Curriculares Nacionais para a Educação Infantil. Outra questão apontada é a necessária articulação com outros espaços de possibilidades pedagógicas e sociais, como parques esportivos, espaços culturais, ambientes públicos de interação.

As leis foram inspiradas nas ideias de Anísio Teixeira, Darcy Ribeiro e Paulo Freire, e a base teórica da perspectiva contemporânea de educação integral conta com contribuições dos estudos de Heidegger, Snyders, Makarenko, Mafesoli, Milton Santos, Deleuze, Spinoza, Tardif, entre outros (MOLL, 2012). Para se colocar em prática a legislação o Programa Mais Educação foi o indutor da política de estado para a educação integral, desenvolvendo atividades diversificadas em escolas de todo o Brasil, levando para os estudantes o contato com a música, com os esportes, com a dança e o teatro, com a pesquisa científica, dentre outras oficinas que possibilitaram a diversificação na formação discente, através do Programa Dinheiro Dentro da Escola (PDDE). Vendo as crianças e jovens de forma integral e buscando desenvolver outras dimensões, para além da cognitiva, o Mais Educação desenvolveu experiências que começaram a formar uma nova ideia de educação através da prática cotidiana.

Para a ampliação do tempo de permanência dos estudantes na escola, e para a diversificação das atividades, necessita-se de uma reorganização e/ou expansão do espaço físico, da jornada dos profissionais da educação, nos investimentos, dentre outros elementos. Desencadearam-se processos de médio prazo que permitiram aos sistemas de ensino e às escolas reordenar seu modus operandi (Ibid., 2012), buscando afirmar o protagonismo dessas na educação. Entende-se que os modelos de educação em disputa no passado e nos dias de hoje, são resultado de um longo processo, onde diferentes perspectivas foram se construindo no tempo e foram fincando raízes nas estruturas de mentalidade. Enfrentamos projetos de educação, de sociedade, de ser humano e de ciência, que inconscientemente (ou conscientemente) vem se construindo em um processo de longa duração. 


\section{3 'UMA' HISTÓRIA DA EDUCAÇÃO INTEGRAL NO BRASIL}

A história da educação no Brasil teve momentos em que a integralidade do sujeito foi considerada de alguma forma e outros em que foram privilegiados determinadas dimensões como a física e a cognitiva. Nessa parte do artigo pretende-se demonstrar alguns recortes históricos que se aproximavam, ou se distanciavam, da perspectiva de educação integral, colaborando ou não para sua futura construção. Visando estabelecer recortes temporais de longo prazo sempre se corre o risco de deixar de fora momentos importantes que poderiam ser tratados, porém se deve respeitar uma linha de análise com os retalhos mais importantes para a construção do objeto de pesquisa (BURKE, 1992). Pretende-se aqui mapear diferentes momentos e perspectivas educacionais desde a época colonial até o presente, visando uma análise histórico-cultural que busca formar não "a" história da educação integral no Brasil, mas sim "uma" história baseada em uma conjunção de recortes escolhidos, assim como o trabalho de um bricoleur que cria algo novo a partir de retalhos.

Durante os séculos XVI e XVII ${ }^{5}$ tivemos uma experiência educacional importante do ponto de vista cultural, as regiões das bacias dos rios Paraguai, Paraná e Uruguai eram uma grande fronteira entre espanhóis, portugueses e diferentes grupos indígenas. Para lidar com esse ambiente de tensões a Igreja Católica mandou para a região missionários da Companhia de Jesus, cuja educação visava como objetivos, civilizar e evangelizar, através de processos educacionais de transculturação baseados na prática (KERN, 2010 apud STEPHANOU; BASTOS, 2010, p. 108-120). Ao mesmo tempo, nessa experiência, nota-se traços de hibridismo cultural $^{6}$, onde as técnicas indígenas misturaram-se com as técnicas europeias formando uma sociedade adaptada às novas realidades (facilmente identificada nas práticas de agricultura, música e nas esculturas missioneiras), mas também nota-se a forte aculturação sofrida pelas populações autóctones que tiveram que renunciar a sua visão cosmológica para se adaptar aos preceitos cristãos.

Os séculos XVIII e XIX foram fortemente marcados pelas ideias iluministas que consideravam a educação peça fundamental para a construção das "luzes", o pensamento cartesiano e o seu conhecimento racional do mundo eram os princípios norteadores. O direito a

\footnotetext{
${ }^{5}$ Infelizmente não caberia nessa pesquisa analisar as educações indígenas que são anteriores a colonização, diferentes grupos étnicos com suas especificidades de como o conhecimento é construído, mas tendo em comum a educação pela experiência e observação dos mais velhos, uma educação prática e direcionada para servir as necessidades da vida (MELATTI, 1986).

${ }^{6}$ Sobre a noção de hibridismo cultural ver Burke (2016), onde o contato entre as culturas faz com que ambas se modifiquem formando uma outra que carrega traços das duas anteriores, além de ser influenciado por expressões individuais que podem carregar outros traços culturais.
} 
uma mesma educação para todas as classes não era ideia compartilhada por todos iluministas. Na prática não havia a preocupação com a luta pelo desenvolvimento de todas as partes do corpo social e sim a elitização da educação e do ambiente escolar, a elite esclarecida e o povo preparado para os serviços pesados e manuais (PALLARES-BURKE, 2001, p. 53-66). Desse modo a educação no Brasil manteve-se um empreendimento para as camadas sociais da elite, uma educação aos pobres, outra para os poderosos, mentalidade que se encontra viva em muitos projetos de educação que pretendem sucatear, e efetivamente vem sucateando, a educação pública.

O avanço no âmbito da educação pública e compulsória não se baseou nas ideias iluministas de construção de valores como liberdade, autonomia e ecumenismo racional, e sim através dos ideais autoritários de estados centralizados que tinham preocupação com a manutenção da ordem social. Preocupados com o controle sobre o povo, enfatizando a obediência, as regras e deveres, criou-se a ideia de educação pública não como emancipação intelectual, mas como controle social (Ibid., 2001).

Durante o período imperial do Brasil começou a pensar-se acerca da necessidade de escolarização da população, com o estado reconhecendo seu papel no processo a instituição escolar foi ganhando importância na formação das gerações futuras. Questionamentos como para quem e para que servia a educação achavam respostas que excluíam negros, índios, mulheres e pobres. As classes economicamente subalternas não deveriam passar das "escolas de primeiras letras", aprendendo a ler, escrever e contar, e então se inserir no mundo do trabalho marcando uma forte elitização da educação (FARIA FILHO, 2000 apud LOPES; FARIA FILHO; VEIGA, 2000, p. 135-150).

A educação durante o Império era necessária para a formação do Estado Nacional, uma estratégia para acelerar o processo civilizatório do povo brasileiro e de seu "branqueamento cultural". A ideia de o progresso vir por meio das letras aumentou a importância da educação, colocando a instituição escolar enquanto espaço formal e os outros ambientes educativos de forma inferiorizada. Aumentou-se consideravelmente os conteúdos curriculares, acompanhando a lógica iluminista que se expandia para o mundo (Ibid., 2000).

Até as décadas finais do século XIX a maioria das escolas eram particulares (domésticas) e poucos eram os professores com vínculo com o estado, a construção de espaços formais era uma necessidade do aumento do número de alunos. Em São Paulo, na década de 1890, foram feitas as primeiras construções públicas denominadas "grupos escolares", visavam 
a expansão do ideal republicano. Essas escolas se estruturavam de forma seriada, racionalizando o tempo, espaço e o trabalho dos professores (Ibid., 2000).

A questão do tempo está no cerne da modernidade, devendo ser utilizado ao máximo para a produção e para a produtividade. Quanto tempo era interessante os alunos ficarem na escola ou fora dela? A resposta a essa questão dependia da camada social na qual o aluno era inserido. Devemos ter em mente que o tempo escolar está em constante construção, leva em consideração os outros tempos sociais para a organização de currículos e programas buscando suprir necessidades específicas.

A modernidade mudou efetivamente a vida das pessoas, sobre tudo nos centros urbanos. $\mathrm{O}$ século XX trouxe os preceitos higienistas, a destruição dos cortiços, a ocidentalização cultural e a nova rotina das cidades colocava desafios diferentes para a educação. Nas primeiras décadas desse século a ordem e a disciplina eram princípios buscados pela sociedade, pois almejava-se construir um disciplinamento mental e físico do indivíduo. Nesse sentido entrou nas discussões pedagógicas a ideia de normatizar a escrita através da caligrafia. A nova escrita seria expressão do moderno por ser mais legível, homogênea e impessoal, assim como a máquina de escrever, o que melhorava a eficiência no trabalho (VIDAL, 1998).

O controle social do corpo e a nova cultura escolar (grupos escolares, ensino seriado, especialização docente) queriam a racionalização da educação. A caligrafia não era só a mecanização da letra mas de toda a pessoa, a disciplina do traço se associa ao disciplinamento mental e a disciplina do falar associada à do escrever (Ibid., 1998).

A educação escolar das classes populares consolidou-se como uma exigência do mundo do trabalho, e nessa lógica o ensino tinha de ser precário, com poucas horas por dia e poucos anos de escolarização. A elite historicamente tem uma educação com tempo integral em termos de jornada, com número maior de anos letivos, contemplando acessar o nível superior e especializações subsequentes (GIOLO, 2012 apud MOLL, 2012). Atualmente as camadas médias e altas da população complementam o tempo escolar de seus filhos com outras atividades no "contraturno", a grande maioria pagas e oferecidas pela iniciativa privada (MOLL, 2012).

O Brasil tem um histórico de práticas educacionais que se preocuparam com o aumento da carga horária do ensino público, as Escolas-Parque de Anísio Teixeira e os Centros Integrados de Educação Pública (CIEP’s) de Darcy Ribeiro são referência nesse sentido. Desde essas primeiras experiências percebeu-se a educação integral pública como um enfrentamento 
das desigualdades sociais, das distâncias entre os setores sociais mais carentes e os mais privilegiados economicamente, e preocupada com as diferentes dimensões do educando.

As experiências educacionais de Anísio Teixeira no Rio de Janeiro nos anos 30 e final dos 50, e na década de 50 na Bahia, demonstram claramente uma preocupação com uma educação integral e pública. Em 1931, enquanto diretor geral da Instrução Pública do então Distrito Federal, defendia um tipo de escola que ensinasse a viver melhor e promovesse o desenvolvimento individual através dos cuidados com a higiene, com os hábitos de leitura e estudo, estimulando a indagação e a crítica, a meditação e o pensar (TEIXEIRA, 1997).

$\mathrm{Na}$ década de 50, na Bahia, Anísio criou o Centro Educacional Carneiro Ribeiro, conhecido como escola-parque. O complexo educacional idealizado era composto por quatro escolas-classe e uma escola-parque com os seguintes setores: pavilhão de trabalho; setor socializante; pavilhão de educação física e recreação; biblioteca; setor administrativo; teatro e setor artístico. As escolas-classe alternavam o horário de utilização da escola-parque. Focavam na busca da autonomia e nos "centros de interesse", substituindo as aulas teóricas pela prática de atividades em grupos de pesquisa (ÉBOLI, 1983).

Essas marcas históricas no Rio de Janeiro influenciaram durante os anos 80 e 90 outra proposta de educação integral. Em duas gestões estaduais (83/86 e 91/94, ambas tendo Leonel Brizola como governador) foram criadas escolas públicas de tempo integral, os CIEP's (Centros Integrados de Educação Pública), que tinham concepções administrativas e pedagógicas próprias e pretendiam promover uma educação de mais qualidade ${ }^{7}$. Essas iniciativas sintetizavam um problema real, que era a inadequação do modelo de escola vigente para absorver as grandes massas da população brasileira que chegavam às escolas públicas urbanas, sendo necessária uma redefinição do papel da escola.

A idealização dos CIEP's (projeto arquitetônico de Oscar Niemeyer) contou com a coordenação de Darcy Ribeiro, inspirado em Anísio Teixeira, onde pretendia-se formar uma escola democrática com funções sociais e pedagógicas ampliadas, com um turno único (8h17h) e com linhas de ação nas áreas de instrução, saúde e cultura. A concepção básica apresentada no Livro dos CIEP's (RIBEIRO, 1986) era uma proposta contra a escola elitista que era estruturada mais para expulsar do que para absolver as classes populares.

As experiências das escolas de tempo integral serviram para obter diagnósticos e propostas para a educação, construindo aberturas políticas e recuperando vivencias dos

\footnotetext{
${ }^{7}$ Sobre o tema ver: Secretaria Estadual de Educação-Balanço da Educação no Estado do Rio de Janeiro, 1994.
} 
períodos democráticos anteriores. Sendo experiências desencadeadoras do ponto de vista político e administrativo. Conforme o debate foi evoluindo percebeu-se que a resolução para os problemas da educação no Brasil não perpassa exclusivamente pelo aumento da carga horária, e sim por uma reestruturação da concepção de educação que proporcione encararmos as desigualdades sociais.

O conceito dessa perspectiva contemporânea de educação integral trazido por Ana Maria Cavalieri no Dicionário Trabalho, Profissão e Condição Docente ${ }^{8}$ organizado pela Universidade Federal de Minas Gerais concebe a ação educacional envolvendo diversas dimensões da formação dos indivíduos, atuando em diferentes aspectos da condição humana, tais como os cognitivos, emocionais e societários. Apresenta um sentido de religação da ação intencional da escola com a vida de forma ampla, uma prática político-social que visa interferir não só nas pessoas, mas na sociedade como um todo, conceito marcado pelo pensamento de J. Dewey. Inicialmente a discussão era em aumentar o tempo de permanência diária na escola, objetivando enfrentar as desigualdades educacionais relacionadas às desigualdades sociais.

Em 2007 o Programa Mais Educação é proposto como possibilidade de construção da agenda para a educação integral pública, com as tarefas de mapear as experiências existentes, reavivar a memória histórica e incentivar a construção de um modus operandi. O programa instala-se em escolas com baixo "Índice de Desenvolvimento da Educação Básica", dentre outros critérios de seleção, para assim dar ênfase onde possa ser prioritariamente necessário. Moll (2012, p.135) apresenta os objetivos do programa trazidos pelo Decreto Presidencial n. 7.083 , de 27 de janeiro de 2010 no seu artigo $3^{\circ}$, onde aparece a formação de uma política nacional de educação integral, a promoção do diálogo entre saberes locais e conteúdos escolares, aproximação entre escola e comunidade, disseminação das experiências e fomentar programas de desenvolvimento da saúde, cultura, esporte, direitos humanos, educação ambiental, entre outras áreas que colaborem do desenvolvimento do ser de forma integral. O PME amplia tempos e espaços, como os compromissos sociais da escola que associada com outras políticas sociais e às especificidades das comunidades, busca a melhoria da qualidade da educação.

\footnotetext{
${ }^{8} \mathrm{O}$ dicionário se encontra disponível no link: 〈http://www.gestrado.net.br/?pg=dicionario-apresentacao $>$.
} 


\section{OS (DES)CAMINHOS DA EDUCAÇÃO INTEGRAL BRASILEIRA}

Atualmente estamos em um momento crucial para o programa nacional de uma educação integral pública e de qualidade devido a descaminhos na política nacional. O novo Ministério da Educação (formado pela gestão Michel Temer, cujo mandato presidencial começou após o impedimento ilegítimo de uma presidenta eleita) aponta prioridades distintas para o universo do ensino, focando no letramento e em uma lógica mercantil. Por outro lado, as propostas que contemplam uma visão de educação baseada no desenvolvimento das múltiplas dimensões do educando e com a consequente necessidade de aumento da carga horária diária para sete horas vêm se multiplicando em esferas estaduais e municipais.

O Estado da Bahia apresentou experiências interessantes se tratando de uma educação integral pública, por meio dos incentivos trazidos pelo Programa Mais Educação desenvolveu o Programa de Educação Integral (ProEI) ${ }^{9}$ em 2014, atuante até os dias atuais. O primeiro ano foi um processo de adaptação onde se manteve a lógica de turno regular e contraturno com as atividades diferenciadas, e a partir de 2015 se está quebrando essa diferenciação. As próprias escolas vêm dando suas percepções sobre os impactos do programa, o principal retorno apontado é em relação a própria postura dos estudantes, notando-se melhoras na maneira como se relacionam e na criação de um sentimento de pertencimento às instituições.

A Prefeitura de São Paulo ${ }^{10}$, no dia 05 de fevereiro de 2016, fez o lançamento do Programa São Paulo Integral de construção da agenda de educação integral na cidade, apresentando como principais diretrizes a ampliação da jornada escolar para sete horas diárias e a reorganização da matriz curricular. A iniciativa foi aberta para a consulta pública no ano de 2015 e reflete as orientações gerais do programa federal Mais Educação. Inicialmente foram 110 escolas municipais de Educação Infantil e Ensino Fundamental em SP capital, os dados desse primeiro ano serão analisados apontando pontos negativos e positivos.

A Comissão de Educação, Cultura e Esporte (CE) do Senado Federal aprovou um relatório $^{11}$, no dia 08 de dezembro de 2015, que aponta como primeira das catorze recomendações a transformação do Programa Mais Educação em política de estado, buscando fontes permanentes e novas de financiamento (como as provenientes do Fundo Social do Pré-

\footnotetext{
9 Ver: 〈http://institucional.educacao.ba.gov.br/proei> e 〈http://educacaointegral.org.br/experiencias/bahia-oscaminhos-da-implementacao-de-um-programa-de-educacao-integral/>.

${ }^{10}$ Ver: <http://educacaointegral.org.br/noticias/sao-paulo-faz-lancamento-de-seu-programa-de-educacao-integral/ $>$.

11 Ver: <http://www12.senado.leg.br/noticias/materias/2015/12/08/escolas-em-tempo-integral-podem-seradotadas-como-padrao?utm_source=facebook $>$.
} 
sal, o que cada dia se torna mais distante devido as novas políticas para esse fim). O relatório foi produzido através de audiências públicas com especialistas e gestores da área da educação, visando cumprir a meta 6 do Plano Nacional de Educação e ter como padrão escolas em tempo integral.

Outro ponto positivo em relação a construção da educação integral no Brasil é a Proposta de Ementa Constitucional (PEC) 28/2015 que tem por objetivo a progressiva universalização da educação básica em tempo integral ${ }^{12}$. Hoje em dia, pouco mais de $34 \%$ das escolas oferecem tempo integral e $12 \%$ dos alunos frequentam, os discentes brasileiros estão entre aqueles com menor tempo de permanência diária na escola (cerca de 4 horas) comparado às experiências internacionais.

A segunda versão da Base Nacional Comum Curricular (BNCC), apresentada no dia 03 de maio de 2016, aponta avanços na construção da perspectiva da educação integral. O texto foca nos direitos à aprendizagem e desenvolvimento enquanto processos contínuos, levando em conta a formação integral do ser humano. A organização da Base foi apresentada por etapas e não áreas de conhecimento, priorizando o educando e suas necessidades ao invés da aquisição descontextualizada e fragmentada dos conteúdos ${ }^{13}$.

No ano de 2016 presenciamos um conjunto de medidas que colocam-se nos descaminhos da construção de uma educação integral pública e de qualidade. Com a situação do processo a educação corre o risco de recorrer a já esgotada concepção mercadológica, tendência que pode ser visualizada através do documento intitulado "A Travessia Social”, onde o programa pmdebista ${ }^{14}$ deixa claro que a questão econômica se sobrepõe à questão social. Algumas medidas apresentadas são a bonificação dos professores pelos resultados, a reforma do Ensino Médio (denominado erroneamente de Segundo Grau) através da reestruturação do currículo focando no ensino profissionalizante e nas necessidades dos mercados locais. Todas essas medidas são criticadas por especialistas, a bonificação é uma falsa valorização que dificulta a construção de planos de carreira, a reestruturação do Ensino Médio de caráter mercadológico tende a afastar os grupos sociais mais carentes do acesso ao Ensino Superior os direcionando exclusivamente ao mundo do trabalho ${ }^{15}$.

\footnotetext{
12 Ver: http://www12.senado.leg.br/noticias/materias/2016/02/03/pec-determina-ampliacao-da-educacao-basicaem-tempo-integral

${ }^{13}$ Ver: http://educacaointegral.org.br/noticias/formacao-integral-e-foco-proposta-formativa-em-nova-versao-da$\underline{\text { bncel }}$

${ }^{14}$ Ver: $<$ http://www.cartaeducacao.com.br/reportagens/conheca-as-propostas-do-pmdb-para-a-educacao/>.

15 Ver: <http://educacaointegral.org.br/noticias/especialistas-temem-retrocesso-na-educacao-posse-de-governointerino/>
} 
O Ministério da Educação desde o começo de 2016 faz cortes em programas como o Mais Educação, o que pôde ser notado já nos pe. O MEC, no dia 14 de abril de 2016, publicou uma portaria ${ }^{16}$ que estabeleceu novas regras para o programa, as principais alterações são referentes ao conteúdo, ao financiamento e a forma de inscrição das escolas. As alterações vinham reforçando o letramento e acompanhamento pedagógico deixando outros campos em segundo plano, afastando-se da perspectiva contemporânea de educação integral. A disputa de projetos de sociedade por trás dessas mudanças interfere diretamente na visão de escola que vivenciamos, devemos afirmar a diversificação das atividades oferecidas para proporcionarmos aos alunos o desenvolvimento de suas múltiplas capacidades.

\section{CONCLUSÕES}

A educação integral pública e de qualidade é um direito do cidadão brasileiro e uma possibilidade para a histórica crise educacional. Reestruturar o tempo escolar e o currículo é fundamental para enfrentar a lógica que coloca os conteúdos e disciplinas no centro do processo educacional e não o sujeito. Ao ver a centralidade do estudante devemos nos preocupar com o desenvolvimento de todas as suas dimensões constituintes, física, emocional, mental/cognitiva, transpessoal e socioambiental.

Devemos encarar os projetos para a educação no Brasil como uma disputa de projeto de país. Historicamente a educação está intimamente ligada a projetos de sociedades que se visa construir. Os processos de longa duração vão construindo mentalidades (LE GOFF, 2013) que ficam latentes nas atitudes e percepções de mundo apresentadas pelos seres humanos. Na educação isso fica visível ao analisarmos momentos da história a partir do filtro de análise das disputas de poder da atualidade no campo educacional. Percebeu-se o fortalecimento de uma visão de educação mais libertadora, que foca no sujeito e não no conteúdo, que procura desenvolver capacidades como a autonomia e o senso democrático, que se preocupa com o estudante como um todo, físico, emoção, mente-cognição, transcendente e social. Ao mesmo tempo há quem defenda uma educação conservadora, que estipula como finalidade do processo educacional a resolução de demandas do mercado, onde o estudante é preparado não para a vida, e sim para uma carreira profissional.

Podemos fazer uma breve análise de traços de mentalidade notados em práticas históricas da educação brasileira que perduram nessa disputa de projetos político-pedagógicos de hoje em dia. A primeira empreitada no Brasil de um projeto político-pedagógico pode ser

\footnotetext{
${ }^{16}$ Ver: 〈http://educacaointegral.org.br/noticias/veja-principais-mudancas-mais-educacao-para-2016/>.
} 
considerada as experiências que ocorreram nas missões jesuíticas, onde iniciou-se a preocupação da educação como projeto de sociedade, na época, europeia e cristã. Desde aí notase uma preocupação com a aculturação dos saberes populares em prol do que vem da cultura hegemônica. Apesar disso, há elementos dessa experiência que ligam-na ao projeto de uma educação mais libertadora, a educação desenvolvida pelos jesuítas, mesmo que aculturante, partia do mundo dos indígenas aproveitando a bagagem trazida por esses povos e partindo daí para chegar nos seus objetivos educacionais.

Outra característica importante de se ressaltar, tendo em vista a disputa de projetos para a educação nos dias atuais, é que a discussão sobre universalização e oferta de educação pública no Brasil não esteve atrelada aos ideais liberais, pelo contrário, está intimamente ligada a formação do Estado Nacional e de uma lógica autoritária e centralizadora. Durante o século XIX, com o império e começo da república, a educação tinha como objetivos o controle e a ordem social e não a emancipação intelectual da população. Os estudos avançados eram destinados às elites enquanto o resto da sociedade tinha no máximo as primeiras letras e operações básicas.

Um século de práticas constrói marcas profundas nas estruturas de mentalidade (LE GOFF, 2013), além do mais se levarmos em consideração nossos poucos quinhentos anos de história, assim podemos ver muitos traços dessa perspectiva conservadora de educação em projetos político-pedagógicos da atualidade. Podemos apontar traços vivos desse positivismo nos projetos de sociedade em disputa. O sucateamento da educação pública e o foco na educação profissionalizante são ações no direcionamento de manter a elitização do acesso aos mundos mais letrados e científicos, construindo uma marginalização do acesso ao desenvolvimento das múltiplas capacidades das classes populares.

Não param por aí as marcas de mentalidade dessa pedagogia tradicional defendida nesse projeto conservador de sociedade ainda vivo. Com o aumento das descobertas científicas no século XIX a lista de conteúdos para se desenvolver na educação era cada vez maior, o que tirou qualquer espaço nas práticas educacionais que não fosse para demonstrar todo o acúmulo de conhecimento (o que sabemos ser um mito, SANTOS, 2008), o sujeito foi cada vez mais marginalizado no processo. Esse posicionamento pode ser visto nos que defendem uma educação tecnicista, assim como nos que pautam a educação em parâmetros tradicionais.

Esses moldes modernos do século XIX estão muito presentes nos paradigmas dominantes, há quem ainda defenda a racionalização da educação através de lógicas como fragmentação do tempo e dos saberes, controle do corpo, construção de currículos baseados em 
conteúdos e não em competências e processos cognitivos. Analisam a qualidade da educação através de métodos quantitativos como exames nacionais e índices de letramento e competências matemáticas básicas, esquecendo de todo o restante do desenvolvimento humano.

Como marca importante na mentalidade nacional de educação no sentido de construção de uma sociedade menos desigual e que respeite o ser humano, destacamos as experiências idealizadas por Anísio Teixeira. Construiu marcas não só na mentalidade como nas próprias políticas públicas em educação, levantou pautas como o aumento da carga horária diária na escola (fundamental para melhorar as condições sociais das populações subalternas), quando pensou na divisão das quatro escolas regulares e uma Escola-Parque possibilitou o espaço e as discussões pedagógicas sobre a diversificação das atividades oferecidas aos educandos, aproximando-os de uma formação mais integral que levava em conta não somente o desenvolvimento cognitivo.

Durante as experiências que Anísio Teixeira encabeçou na Bahia e no Rio de Janeiro foram abrindo-se discussões para, pouco a pouco, as ideias de uma formação integral em tempo integral, que oferece a possibilidade de desenvolver as potencialidades dos alunos em diferentes áreas, ciência, artes, habilidades manuais, habilidades técnicas, ir ganhando adeptos e defensores a nível nacional. O que durante a década de 1980 verificou-se nas experiências de Darcy Ribeiro com os CIEP's no Rio de Janeiro foi uma demonstração da maturidade que atingiu a ideia de educação integral sendo feita uma proposta de política pública para todo o estado. Podemos levantar críticas em relação ao alcance da proposta em sua ideia inicial, mas temos que ressaltar que sua falha veio através da vitória na sucessão política de um projeto de educação tradicional que sucateou as iniciativas anteriores.

Uma vez mais um projeto político-pedagógico conservador demostrou-se forte para desmanchar as iniciativas de uma educação libertadora e de cunho integral, e atualmente estamos passando pelo mesmo processo. Durante mais de uma década foram construindo-se experiências em políticas públicas através do Programa Mais Educação, onde além de se aumentar o tempo de permanência diária dos alunos na escola, proporcionou-se uma diversificação de atividades oferecidas (através das oficinas), que possibilitavam o desenvolvimento de outras dimensões nos educandos que não só a cognitiva.

A partir do ano de 2016 estamos vendo um avanço de uma educação tradicional que pretende descaracterizar os avanços da educação integral. Podemos notar isso nas mudanças no próprio Programa Mais Educação onde cada vez mais o letramento e as aulas de reforço tiram espaço das outras atividades, correndo o risco de cair no tão criticado "mais do mesmo". É 
necessária a vigília constante para o acréscimo de horas não se tornar uma tortura aos alunos, para que a escola não se reforce como um centro de formação de mão de obra barata para as novas demandas do sistema capitalista.

Avançamos nos últimos anos na construção de uma agenda de educação integral em nível nacional, mas as conquistas alcançadas têm seus alicerces frágeis e todos os envolvidos devem zelar por sua expansão. A crise política e econômica que o Brasil passa vem influenciando diretamente os caminhos da educação pública. Ganhou peso no cenário político uma visão conservadora e mercantil que, pouco a pouco, sucateia a educação pública e privilegia os setores privados, carregando a perspectiva de educação bancária tão criticada por Paulo Freire. Devemos tutelar os direitos alcançados para que os avanços sejam políticas de Estado e não de governo, não estando a mercê das crises institucionais.

\section{REFERÊNCIAS}

BURKE, P. (Org.). A escrita da história. São Paulo: Unesp, 1992.

BURKE, P. Hibridismo cultural. São Leopoldo: Unisinos, 2016.

CAVALARI, R. M. F. Integralismo: ideologia e organização de um partido de massas no Brasil (1932-1937). Bauru: EDUSC, 1999.

ÉBOLI, T. Uma experiência de Educação Integral. Rio de Janeiro: FAPERJ. 1983.

EI. Centro de Referência em Educação Integral. Conteúdos pedagógicos- Experiências.

Disponível em: <http://educacaointegral.org.br/experiencias/bahia-os-caminhos-daimplementacao-de-um-programa-de-educacao-integral/>. Acesso em: 14 out. 2017.

EI. Centro de Referência em Educação Integral. Notícias- Reportagens. Disponível em: <http://educacaointegral.org.br/noticias/formacao-integral-e-foco-proposta-formativa-emnova-versao-da-bncc/>. Acesso em: 14 out. 2017.

EI. Centro de Referências em Educação Integral. Notícias- Reportagens. Disponível em: $<$ http://educacaointegral.org.br/noticias/especialistas-temem-retrocesso-na-educacao-possede-governo-interino/>. Acesso em: 14 out. 2017.

EI. Centro de Referência em Educação Integral. Notícias- Reportagens. Disponível em:< http://educacaointegral.org.br/noticias/veja-principais-mudancas-mais-educacao-para-2016/>. Acesso em: 14 out. 2017.

ESTADO DA BAHIA. Secretaria de Educação. Notícias. Disponível em: <http://institucional.educacao.ba.gov.br/proei>. Acesso em: 14 out. 2017.

FOUCAULT, M. A verdade e as formas jurídicas. Rio de Janeiro: Nau, 2003. 
GIOLO, J. Educação de tempo integral: resgatando elementos históricos e conceituais para o debate. In: MOLL, J. et al. Caminhos da educação integral no Brasil: direito a outros tempos e espaços educativos. Porto Alegre: Penso, 2012. p. 94-105.

KERN, A. A. A educação do outro: jesuítas e guaranis nas missões colônias platinas. In: STEPHANOU, M.; BASTOS, M. H. C. (Org.). Histórias e Memórias da Educação no Brasil - séculos XVI e XVII. 4. ed. Petrópolis: Vozes, 2010. p. 108-120.

LE GOFF, J. História e memória. Campinas: Unicamp, 2013.

MELATTI, J. C. Índios do Brasil. São Paulo: Hucitec Edusp, 1986.

MOLL, J. et al. Caminhos da educação integral no Brasil: direito a outros tempos e espaços educativos. Porto Alegre: Penso, 2012. 504 p.

PAIVA, Thais. Carta Capital. Carta Educação. Disponível em:

$<$ http://www.cartaeducacao.com.br/reportagens/conheca-as-propostas-do-pmdb-para-aeducacao/>.Acesso em: 14 out. 2017.

PALLARES-BURKE, M. L. G. Educação das massas: uma 'sombra' no século das luzes. In: VIDAL, D. G.; HILSDORF, M. L. S. (Org.). Brasil 500 anos: tópicos em história da educação. São Paulo: Edusp, 2001. p. 53-66.

REDAÇÃO. Senado Federal. Senado Notícias. Disponível em> <http://www12.senado.leg.br/noticias/materias/2015/12/08/escolas-em-tempo-integralpodem-ser-adotadas-como-padrao?utm_source=facebook>. Acesso em: 14 out. 2017.

REDAÇÃO. Senado Federal. Senado Notícias. Disponível em: $<$ http://www12.senado.leg.br/noticias/materias/2016/02/03/pec-determina-ampliacao-daeducacao-basica-em-tempo-integral>. Acesso em: 14 out. 2017.

RIBEIRO, D. O Livro dos CIEP's. Rio de Janeiro: Bloch, 1986.

SARAIVA, K. Diário de uma pesquisa off-road: analise de textos como problematização de regimes de verdade. In: FERREIRA, T.; SAMPAIO, S. M. V. (Org.). Escritos metodológicos: possibilidade na pesquisa contemporânea em educação. Maceio: EDUFAL, 2009. p.13-34.

TEIXEIRA, A. Educação para a democracia. Rio de Janeiro: Ed. UFRJ, 1997.

Recebido em: 23 de julho de 2018.

Aprovado em: 15 de outubro de 2018. 